\title{
Multi-layered Trajectories of Water and Sanitation Poverty in Dar es Salaam
}

Pascale Hofmann, Development Planning Unit, UCL, p.hofmann@ucl.ac.uk

\begin{abstract}
Many cities in the Global South keep on expanding without adequate infrastructure leaving a large number of people to experience varying degrees of water and sanitation poverty. Dar es Salaam, Tanzania, has been subject to numerous interventions aimed at improving service provision across the city with mixed and overall limited results. Most of them are driven by popular definitions of urban water and sanitation poverty that portray the problem in a simplified way. It is often assumed that once people gain access to some form of improved access to basic services, this access is sustained over time. Instead, the urban poor experience differing journeys as they 'travel' in and out of water poverty but their trajectories are insufficiently understood. This chapter applies a relational approach to unfold a select number of trajectories from people living in a low-income community in Dar es Salaam. The stories illustrate how and why certain households and individuals are able to move out of urban water and sanitation poverty while others are not and thus offers insights into the dynamic interplay between individual and collective agency. This highlights different and changing degrees of urban water and sanitation poverty in a settlement and reveals the power dynamics that condition inequalities and shape people's trajectories over time. These narratives offer a nuanced and multi-layered understanding that challenges fixed universal approaches.
\end{abstract}

\section{Introduction}

Despite substantial investment and numerous interventions over the last few decades, estimates suggest that about 663 million people are still without improved access to water and approximately 2.4 billion people lack access to improved sanitation, with Sub-Saharan Africa (SSA) recording the lowest levels of access (UNICEF and WHO 2015). Many cities in the Global South experience urbanisation without adequate infrastructure, leading to fundamental intraurban disparities whereby a large number of people suffer from varying degrees of service deprivation. Urban water and sanitation poverty (UWSP) has received different and often competing definitions ${ }^{1}$ and the absence of a common understanding adds to the challenge of

\footnotetext{
${ }^{1}$ See the special issue of the International Journal of Sustainable Urban Development on Urban Water Poverty $(2011,3: 1)$ edited by Allen and Bell for different perspectives on the issue.
} 
estimating and tackling current shortfalls. Tanzania, similar to other SSA countries, has been undergoing rapid urban expansion ${ }^{2}$ while access to improved water sources in towns and cities has seen a decline since 1990 (Potts 2012; www.e-geopolis.eu; UNICEF and WHO 2015).

Figures above are based on the well-established definition of the Joint Monitoring Programme for Water Supply and Sanitation (JMP), which characterises 'improved' access as having an improved drinking water and sanitation facility within one kilometre allowing up to 30 minutes to use the facilities. This, however, is no guarantee for satisfactory or adequate access, neither an all-encompassing way of scrutinising UWSP. For instance, an improved water source might not necessarily provide safe water on a regular basis or be affordable for everyone (Hofmann 2011). As a consequence, improved access is not equivalent to adequate access and it is widely recognised that we need to aim for the latter, particularly to tackle water-related diseases (JMP Technical Task Force 2011; UNICEF and WHO 2011; WaterAid 2013; WHO 2012).

Adequate access to water supply and sanitation (WSS) implies that the service provided is safe, sufficient, regular, affordable and accessible (Hofmann 2011; UNICEF and WHO 2012). These aspects, now incorporated into the Sustainable Development Goal for WSS, are fundamental to the realisation of the right to safe drinking water and sanitation (WHO and UNICEF 2015). UN recognition of this right in 2010 constitutes a significant shift in the debate around water and sanitation, i.e. how these services ought to be delivered and whether water specifically should be considered as a good to be sold.

As a normative concept, UWSP and its experience needs to be captured in relative terms, specifying who suffers it, where, when and why by paying particular attention to the sociocultural context where it manifests itself. In an urban setting, those considered water and sanitation poor typically belong to lower-income groups largely residing in informal settlements with deficient access to formal service provision, where facilities at the household level are rare. In cities like Dar es Salaam, the public utility is seriously underserving its citizens and large parts of the population are affected by intermittent water supply. Only an estimated $50 \%$ of inhabitants are connected to the public water network and $10 \%$ to underground sewers (Kombe et al. 2015). However, not all residents insufficiently served by the utility can be considered water and sanitation poor; those with the capacity to gain adequate access through alternative service providers without compromising on other needs cannot if their lives are not adversely affected. Instead, living in water and sanitation poverty refers to those that are

\footnotetext{
2 Urban expansion is not the same as or a consequence of rapid demographic growth but refers to multiple processes that change the spatial structure of cities over time (Lincoln Institute of Land Policy 2015).
} 
vulnerable towards unsafe, insufficient/irregular and costly services with negative impacts on their health, livelihood and well-being.

Drawing from fieldwork conducted in Dar es Salaam³, the chapter examines how individual trajectories of UWSP are influenced by the interplay between everyday hydro-social relations and external structural conditions (Lamsal 2012; Saatcioglu and Corus 2014). Tracing personal journeys in and out of UWSP over time helps to contrast and dispute popular reductionist definitions around lack of access to basic services (Maynes et al. 2008). A relational approach that plays particular attention to the dimensions of time and space (Somers 1994) is used to unfold a number of multi-layered trajectories in Kombo, a low-income settlement in Dar es Salaam. With its diverse landscape of water supply and sanitation interventions initiated by various actors it offers a suitable environment where different trajectories can be observed. The next section problematizes the limitations of prevailing definitions and approaches. This is followed by an elaboration of the relational approach adopted before applying it to examine life stories of a select number of residents from Kombo, a low-income settlement in Dar es Salaam where access to services from the utility are marginal.

\section{Urban Water and Sanitation Poverty}

Governments and international aid agencies alike commonly understand UWSP as an issue of maldistribution, whereby people are deprived of adequate access to basic services. While this is significant, many would argue that understanding UWSP simply in economic and distributional terms is not sufficient as struggles around access are frequently related to social and political marginalisation and exclusion (Mitlin and Satterthwaite 2013). Acknowledging the social implications of insufficient access to water and sanitation caused by 'poverty, inequality and unequal power relationships [....] exacerbated by social and environmental challenges' puts the spotlight on misrecognition and misrepresentation (OHCHR et al. 2010, 1). The human rights framework clearly highlights participation, non-discrimination and accountability as key variables to the attainment of human rights (UNICEF and WHO 2012). This is not to downplay

\footnotetext{
${ }^{3}$ The research is part of an Engineering Doctorate with funding from the Engineering and Physical Sciences Research Council (EPSRC). Part of the study examining different institutional discourses on urban water poverty is published elsewhere (see Hofmann forthcoming 2016). The fieldwork in Dar es Salaam referred to in this chapter was undertaken during four visits between May 2014 and June 2015 consisting of institutional interviews (with representatives from multi- and bi-lateral development organisations, national and international Non-Governmental Organisations (NGOs), consultancy firms, local and national government); focus group discussions (FGDs) with local residents, including Kombo; community meetings, transect walks, in-depth interviews with local residents, informal conversations and personal observations.
} 
the importance of distribution; however, maldistribution (of WSS) is often reinforced by conditions of misrecognition and lack of participation (Fraser 2007), an aspect frequently overlooked in prominent conceptions of UWSP (Hofmann 2013).

Interviews with policy makers and key shapers of WSS interventions in Dar es Salaam ${ }^{4}$ revealed that dominant views neglect the temporality of this phenomenon as they commonly assume that once people gain access this is sustained but many of the urban water and sanitation poor follow trajectories where they move in and out of UWSP for a variety of reasons. What is more, those living in UWSP are treated by and large as a homogeneous group with limited understanding of diverse social identities and distinct trajectories. In Dar es Salaam, policy makers and service providers characterise the urban water and sanitation poor mainly in relation to their lack of financial capacity to meet their needs (Interview with utility employee, August 2014; Interview with Ministry of Water employee, February 2015). This treats 'all who belong to a particular social category as sharing equally the particular natural attributes (positive or negative) specific to it. Categorical attributes are often used for the construction of inclusionary/exclusionary boundaries that differentiate between self and other, determining what is 'normal' and what is not, who is entitled to certain resources [or services] and who is not' (Yuval-Davis 2006, 199) and is used to justify differential access in WSS.

UWSP is frequently associated with wealth and income inequalities (Ekers and Loftus 2008), though there is some increasing recognition of age and gender-based needs, particularly among the international development community, with several WSS initiatives focusing on women and children (Batty et al. 2011; Interview 14 and 25, August 2014; Gosling 2010; SNV, WaterAid and UNICEF 2008). Some initiatives across the Global South, often supported by development organisations, have problematized the issue of land tenure and tenure security in relation to WSS (Aristizabal 2004; Homeless International 2011; Scott et al. 2013; Scott 2013). Nevertheless, a sole focus on single elements of people's identity provides a limited understanding of the problem that could marginalise those differing from what is considered 'the norm' in other aspects, e.g. race/ethnicity, religion or ability (Dhamoon 2011; Hancock 2007). As a result, several scholars have voiced growing dissatisfaction with the independent analytical treatment of homogenous categories such as 'gender' or 'class' and the limiting explanatory power of this approach (Levy 2010; Yuval-Davis 2006). As argued by Symington: 'people live multiple, layered identities derived from social relations, history and the operation

\footnotetext{
${ }^{4}$ Among those interviewed were representatives from DAWASA and DAWASCO (the two utility agencies), the Ministry of Water, EWURA (the national regulatory authority), local government, multi- and bilateral aid agencies, international and local NGOs and consultancy firms.
} 
of structures of power. People are members of more than one community at the same time, and can simultaneously experience oppression and privilege' $(2004,2)$.

This calls for a shift from universalising approaches that single out one category as most relevant and explanatory to considering multi-layered factors, relations and intersections. This chapter aims to re-conceive UWSP by looking at everyday practices and quotidian trajectories from a relational perspective. This will lead to a more disaggregated understanding of 'the urban water and sanitation poor' and shed light onto the 'multiple axes of inequality' that influence people's trajectories (Prins 2006). The following section will advance on a relational approach by drawing on some of the intersectionality literature.

\section{Revisiting UWSP: From Intersectional Identities to a Relational Approach}

Intersectionality or intersectional analysis originally emerged from research on gender and race in the United States and the discontent with single-axis analytical frameworks but has since been more widely conceptualised and applied (Hancock 2007; for some useful historical reviews see McCall 2005; Nash 2008; Prins 2006). The key argument of intersectionality is that people's identities cannot be captured or reduced to a single category but need to be defined by considering intersections of multiple identities and relations. Part of the literature on intersectionality insists that in order to analyse inequality and marginalisation it is not sufficient to solely focus on marginalised groups but to further study those where power and privilege prevail (Choo and Ferree 2010; Christensen and Jensen 2012; Yuval-Davis 2011). While this can be important, there already exists a broad albeit unsophisticated awareness of who lives in water and sanitation poverty in an urban context. It is a much more nuanced and disaggregated understanding of the different trajectories of UWSP within such broad grouping that is currently lacking.

In the Global South, the concept has been embraced largely by feminists since the early 2000s but its application in relation to issues of environmental injustice and inequality, particularly with regard to water and sanitation, has been limited (see Seward 2014; Symington 2004). Different approaches to intersectionality have developed whereby some would emphasise the constitutive role of social categories in people's identities and social inequalities while others downplay their determining character and underline the importance of dynamic relations (Prins 2006).

Over-emphasising categories and individual identities to the detriment of relational aspects run the risk of replicating the approaches that intersectionality is trying to critique (Dhamoon 2011; Nash 2008). In fact, newly created but fixed categories are equally problematic even if informed by aspirations of including those previously excluded (Somers 1994). Instead, people's UWSP 
trajectories are rooted in a particular place, they are multi-layered and they change over time: 'social categories such as race/ethnicity, gender, class, sexuality, and ability are socially constructed, fluid, and flexible; and social locations are inseparable and shaped by the interacting and mutually constituting social processes and structures that are influenced by both time and place,' (Hankivsky 2012, 1713). The investigation of UWSP trajectories thus needs to be embedded within the intersection of time and place as key domains in shaping, challenging and restructuring social relations at the individual as well as the structural level (Yuval-Davis 2006). Methodologically, an integration of time, space and relationality moves away from categorical identities and emphasises the embeddedness of identit[ies] in overlapping networks of relations that shift over time and space' and allows for an understanding of how different trajectories are constituted and reconstituted over time by people's hydro-social relations in a particular historical and spatial setting (Somers 1994, 607). Life stories provide an important means to move beyond individual identities and explore intersecting relations that influence people's trajectories through UWSP. Identity then becomes not a matter of categorisation but of narration. It 'plays a constitutive role but never in the same way' as people's trajectories are multi-layered and dynamic and cannot be classified based on a list of categorical affiliations (Prins 2006, 281).

\section{Trajectories of UWSP in Kombo}

The sub-ward of Kombo5 is an unplanned settlement in Vingunguti Ward, approximately six kilometres from the city centre, within Ilala municipality. It is located next to one of the city's nine wastewater stabilisation ponds established in the area during the 1960s (see Map 1). Kombo largely houses low-income households with a majority of tenants and has seen a large influx of people since the 1980s due to the establishment of nearby industries. Nowadays, only some residents are under permanent employment while many are involved in small enterprises and casual work (CCI, unpublished documentation). With regard to WSS, Kombo is characterised by a diverse range of local government, NGO and international development interventions and local practices that have emerged at different points in time to deal with the inadequate provision of infrastructure and services. Until the 1990s, the few households with utility water connections received regular water supply but most Kombo residents spent up to two hours a day to fetch one to two buckets of water from outside the settlement (Bayliss and Tukai 2011; female FGD, September 2014). By then, coverage levels were notoriously low across the city and the water supply system suffered overall from dilapidation (DAWASA 2000;

\footnotetext{
${ }^{5}$ Kombo was recently sub-divided into two. As the fieldwork commenced prior to this sub-division reference to Kombo includes the newly created sub-ward.
} 
Pigeon 2012). This has led to individuals in the settlement drilling their own boreholes and selling water to others while also attracting mobile water vendors (Bayliss and Tukai 2011; male FGD in Kombo, September 2014).

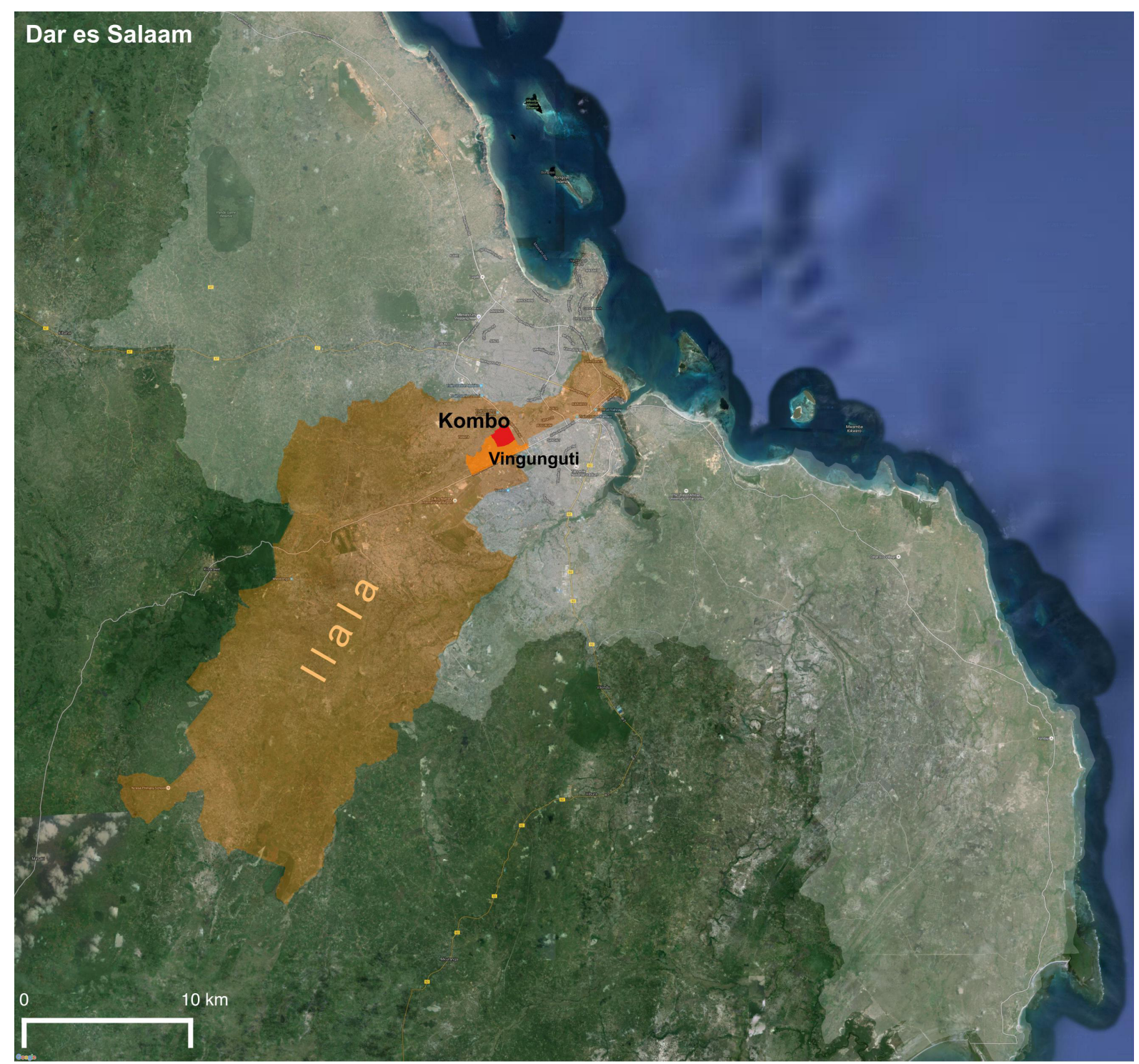

Map 1: Location of Kombo in Dar es Salaam (Map data (C) 2015 Google Imagery (C) 2015 CNES/Astrium, CNES Spot Image, Digital Globe)

Connections to the utility network are still existent (serving approximately 25\% of Kombo's population) but insufficient to meet people's needs. At best, they provide water once or twice a week for a few hours (community meeting in Kombo, February 2015). Since 1998, two boreholes were constructed by Plan International (in 1998 and 2007 respectively) and one by local government, each with a number of public distribution points across the settlement and a few household connections. After the initial setup each scheme has been managed by communities. These interventions have improved access to water but reliance on private boreholes and water vendors is still significant. With regard to sanitation, most households 
depend on simple pit latrines with a few septic tanks and a limited number benefitting from a simplified sewerage scheme implemented in 2014 that connects household toilets to the nearby wastewater ponds using simplified technology.

\section{Multi-layered Life Stories of UWSP}

Below are a number of relational stories from Kombo residents ${ }^{6}$ that illustrate the dynamic interplay between agency (identities and lived lives) and enabling as well as constraining structural conditions, and people's varying influence over their hydro-social relations. The stories highlight different and changing degrees of UWSP in a settlement and reveal multiple power dynamics that condition inequalities and shape people's trajectories.

\section{Mary}

Mary is a landlady that has been able to improve her access to WSS over time (see Figure 1). She and her husband came to the area in 1989 and have built their house incrementally, financed through multiple income-earning activities (including the letting of rooms) and more recently access to micro-credit facilities. She is well established in the community, consolidated through being an active member of the Tanzanian Federation of the Urban Poor (TFUP) since its inception in Kombo in 2011. Initially, the couple let out two rooms but have managed over the years to extend their house and now accommodate a total of 12 tenants. After several years of relying on water sources from outside, they established a yard connection in 2009 from one of the private boreholes in the area and pay a fixed monthly rate of TSh25,0007. In 2014, the couple became one of the beneficiaries of a simplified sewerage pilot scheme initiated by the Cambridge Development Initiative together with the Centre for Community Initiatives (CCI), a local NGO. The system initially connected 20 toilets to the nearby wastewater stabilisation ponds and another 50 connections are underway.

Mary and her husband were able to reduce their level of UWSP largely due to their location within the settlement and tenure status. Tenants are intended beneficiaries but the intervention primarily targeted landlords as the owners of toilet facilities. This was partly because a few of the beneficiaries of the scheme relied on loans to pay a subsidised contribution of TSh40,000 and most micro-credit facilities in Tanzania are aimed at landlords to reduce the risk of nonrepayment (Trémolet and Muruka 2013). Mary and her husband were able to take advantage of these favouring structural conditions to upgrade their simple pit-latrine, address issues of

\footnotetext{
${ }^{6}$ Unless otherwise stated information is based on interviews and focus group discussions with Kombo residents. Their names have been changed for the purpose of anonymity.

${ }^{7}$ At an exchange rate of $£ 1=$ TSh3,200 (September 2015) this corresponds to $£ 7.60$.
} 
recurring floods and eliminate expenses associated with the need for frequent pit-emptying. Conversely, other landlords outside of the project perimeter continue to struggle with the safe disposal and treatment of wastewater.

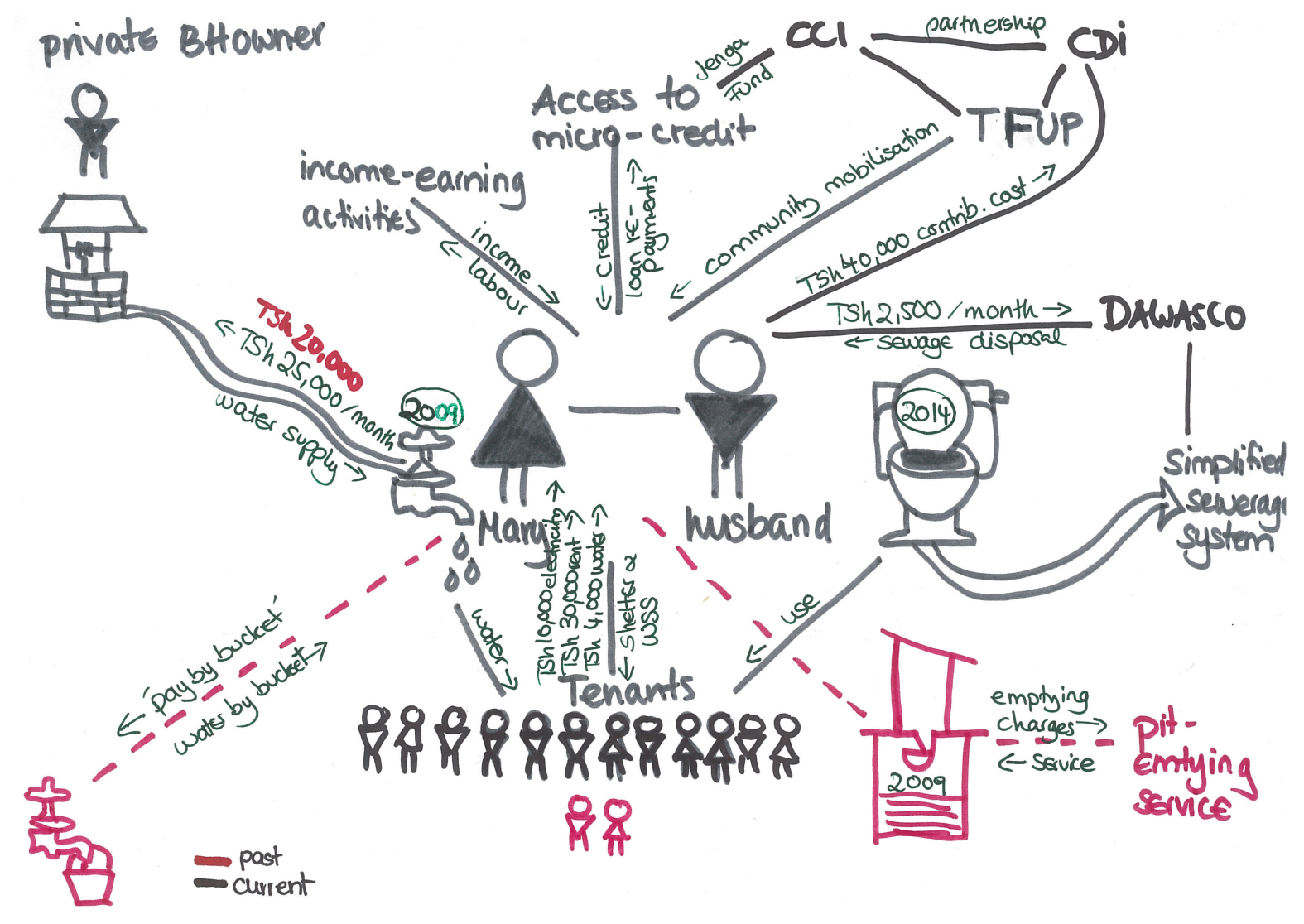

Figure 1: Mary's multi-layered trajectory

One could contend that this has subsequently improved the lives of their tenants, too. Even though they are not charging directly for the improved sanitation facility, joining the scheme led to a rent increase per room from TSh25,000 to TSh30,000 per month, which can be a challenge for many tenants in the city with monthly incomes of TSh50,000 or less (Mkanga and Ndezi 2014). TFUP has been actively involved since the project's inception and advocated against related rent increases but reinforcement has been difficult as the Tanzanian law does not protect tenants against sudden rent increases (informal conversation with TFUP member, March 2015; Trémolet and Muruka 2013). With a start-up cost of TSh40,000 and TSh2,500 spent on monthly service charges, Mary and her husband have already managed to improve their financial situation while the tenants are paying for improved services. A similar picture emerges with regard to water whereby tenant contributions of TSh4,000 each exceed the monthly amount paid to the borehole owner.

Tenants are much more vulnerable and increases in rent could lead to growing levels of UWSP, e.g. they might be forced into seeking cheaper accommodation with poorer access to WSS. The 
relationship between landlords and tenants can play a defining role in people's trajectories (Scott 2013; Stephens et al. 2013). This is significant for an area like Vingunguti with high proportions of tenants and migrant populations, particularly with regard to scaling up initiatives like these. Absent landlords can further increase the danger of 'exploitative landlordism' and proliferate the displacement of tenants (Scott 2013; women FGD in Keko Machungwa, September 2014).

The above illustration establishes that geographic location can pose enabling as well as constraining structural conditions. But Mary's story takes this much further by highlighting multiple important relations, e.g. the intersection of place, time and identity in forming hydrosocial relations. She would not have been able to benefit from the pilot scheme in the same way if she lived elsewhere in the settlement, if she was a tenant or if the intervention happened at a different time. Similarly, the diverse range of income earning activities of both as well as Mary's connectivity within the local community has allowed them to gradually move out of UWSP. In contrast, Joseph, another landlord with a toilet connected to the simplified sewerage scheme, is still struggling. He came to Kombo in 2007 with his wife after selling their house elsewhere in Dar es Salaam. As a former army employee Joseph receives a small pension and rents out two rooms at TSh20,000 each. In contrast to Mary, the couple cannot afford a household water connection but instead rely on private boreholes in the vicinity. Joseph is responsible for fetching water as his wife is too ill to do so and neither of them is currently engaged in any income-earning activity. Any potential to increase the rent is limited as the smell from the nearby ponds renders their property less attractive. While he lives not far from Mary, Joseph is less established and resourceful and has a dependable wife. His agency, i.e. control over his hydro-social relations and the capacity to transform them by taking advantage of favourable structural conditions and resolving adverse ones, is limited (Sewell 1992).

\section{Janeth}

Janeth is a 24-year-old tenant that moved to Kombo with her mother and three siblings in 2007. Since 2009, she has been living alone renting a room near the sewage ponds, an area prone to flooding, and supports herself through money earned from playing football. Janeth joined a local TFUP group in 2013 and has been saving regularly ever since. She accesses water from two sources, a Plan International distribution point and a private borehole. They are both at equal distance but she feels that the quality from Plan International is better and sold at a lower price per bucket although it provides anything but a reliable service. Limiting operating hours and frequent electricity cuts force her to frequently purchase more expensive water from a private borehole. As more people have been moving to Kombo without increasing the capacity of existing infrastructure, problems with community-managed systems have risen and affect 
particularly those residents that access distribution points that are further away from the borehole $^{8}$. Janeth is currently not concerned about improving her access to water, particularly if it increases her expenses, as she is saving up to leave Kombo to open her own business and her consumption levels are comparatively low (20-30 litres per day). However, for residents with large families and those that rely on water for their income-earning activities purchasing by the bucket can be very expensive and time consuming. Mariam, a landlady has been living with her large family in Kombo for years. She accesses water from a private borehole five minutes away and used to spend more than TSh25,000 monthly until she managed to establish an agreement with the borehole owner to pay a monthly flat rate of TSh15,000. This would not suit Janeth's circumstances and neither does it reduce the time dedicated to collecting water. However, for Mariam, who lacks the means to install a household connection, it reduces her expenses and provides a more convenient payment mechanism.

Being a tenant gives Janeth limited influence over housing conditions and services. As the landlord lives off-site, keeping the the pit-latrine that is shared among all six tenants safe and clean poses a challenge. She was fortunate not to incur any rent increases since 2009 but has been a victim of yearly floods until her landlord took flood protection measures in 2014. While her level of UWSP has neither improved nor worsened over the past six years, it was largely her own decision. She has been working towards improving her situation by enhancing her knowledge and skills through TFUP capacity-building activities and increasing her financial resilience through their savings scheme. Both will contribute towards the aim of opening her own shop next year.

\section{Halima}

Halima, an elderly landlady, is one of the private borehole owners in Kombo. The borehole was funded by her son and installed in 2013 to reduce the time spent on fetching water from neighbours. Halima is selling water to others at TSh30 per 20 litres, the same rate charged at the Plan International borehole. She claims selling is not for profit but to cover her electricity bill. Given the above-mentioned restrictions of the Plan International system, many residents are forced to supplement their supply with water from private boreholes like Halima's. Private boreholes currently improve access to water for a substantial number of people in Kombo. But without regulation to guide the position and number of boreholes and prevent from overextraction it is not a system that can be sustainably reproduced. EWURA, the national regulatory authority, has developed guidelines to regulate informal service providers such as private boreholes and water tankers but they lack implementation (Interview with EWURA employee,

\footnotetext{
${ }^{8}$ Community managed systems tend to have one borehole that supplies water to a number of distribution points within the settlement where residents access water.
} 
August 2014). As a consequence, private boreholes emerge unsystematically with no official record of how much water is extracted. This means that Halima's supply is without limits and selling water to neighbours covers all costs incurred to extract water, i.e. electricity. With the installation of her own borehole she is able to dedicate the money previously spent on buying water to other purposes.

However, accessing water for free does not always improve people's level of UWSP. Yahaia, an older resident in Kombo receives water for free from the Plan International borehole because of his age9. Yahaia's ability to benefit from these enabling structural conditions and thus his trajectory of UWSP is closely intertwined with and conditioned by his relationship with others. Due to his restricted mobility he relies on his grandson to fetch water. This has sometimes proven difficult as his grandson lives elsewhere in the settlement and is not continuously available during operating hours. Frequent electricity cuts pose an additional challenge and often require reverting to other sources against payment.

Individual practices like Halima's can seriously impinge on the amount of water available to others and compromise the environmental sustainability of the water source but people tend to be oblivious to wider implications of their own practices. This is further evident in relation to sanitation. Halima has a simple pit latrine that has not been emptied for years as the sandy soil in Kombo makes the faecal sludge seep into the ground. With the majority of households relying on simple pit latrines this is a frequent occurrence while others in lower lying areas tend to open their pits during the rainy season to avoid paying for pit-emptying services. Thus, the risk of groundwater contamination by latrines is high. Many residents, like Halima, do not problematize this habit, which somewhat mirrors the government's lack of priority for sanitation (Thomas et al. 2013). Halima's account emphasises the relevance of relations between people and the environment, which materialise through her environmental interests. Halima has a desire to access water and dispose of wastewater to meet basic needs and improve personal well-being. In the absence of government provision she takes matters into her own hands to the detriment of the environment and potentially other residents.

\section{Discussion and Conclusion}

The life stories above offer interesting insights into the diverse trajectories of UWSP experienced through time on the ground. While Kombo has attracted a range of WSS

\footnotetext{
${ }^{9}$ Water through kiosks used to be provided free of charge until this practice was suspended in 1991 in the name of achieving financial autonomy of the utility (Pigeon 2012). Arrangements are in place whereby the elderly and those with serious illness or disabilities remain entitled to free water.
} 
interventions, the way in which people in the settlement benefit or not is not static and dependent on the dynamic interplay of agency at the micro-level and structures and institutions at the macro-level. Community-managed facilities supposedly provide a durable low-cost solution and are currently the utility's preferred option to provide services to low-income areas in Dar es Salaam (Interview with utility employee, August 2014; GIZ 2013). However, as witnessed through the stories from Kombo, residents do not benefit equally from the community-managed systems. This is partly related to where people live but Yahaia's story demonstrates that his access is not only determined by physical vicinity. What is more, a latent relationship between the state and communities is largely a means to reduce the role of the former by transferring the responsibility to the latter (Allen 2012; see also Walnycki in this volume).

As community-managed systems struggle to operate effectively without the necessary government support to meet the demand of a growing population, it is largely left to the people themselves to activate their right to water but while the whole settlement is considered 'lowincome', people do so with differing ability, opportunity and control. Private boreholes partially fill the gap but leave customers vulnerable to volatile rates, which in Kombo range between TSh30-100 per 20 litres (women and men FGDs in Kombo, September 2014; community meeting in Kombo, February 2015). For Janeth, who lives on her own and consumes less than 30 litres a day, this has not affected her much but for others it can reduce significantly other household expenditures and impact on livelihoods. The 'pay by bucket' approach that is operating at most water sources means that people only access the amount of water they are able to pay for momentarily, which is not necessarily a reflection of how much water is needed, and makes universal arrangements problematic. Residents like Mariam commonly find it easier to pay on a monthly basis whereas others with very limited resources or temporary residents like Janeth prefer to organise their expenses on a shorter-term basis (female FGDs, September 2014; interview with Janeth, June 2015). Both agency and structure can have constraining features as well as enabling abilities. In Mariam's case, an established agreement with the borehole owner allows protection from ad hoc payments and volatile charges in the absence of a regulated service backed up by the State. Her case illustrates how constraining structural conditions at the macro-level can be overcome through the formation of hydro-social relations at the micro-level. Conversely, Mary's story paints a contrasting picture whereby enabling structural circumstances brought about by an intervention can reinforce unequal social relations at the micro-scale, i.e. between landlords and tenants. Evidently, individual trajectories intertwine and influence each other in ways that can move people out of UWSP or aggravate their circumstances. 
Traversing through the different stories reveals their uniqueness while also recognising the influence of social and historical processes on individual lived trajectories embedded in a specific place. Therefore, they offer rare insights into the dynamic relations between the micro and the macro level, or as Maynes et al. call it 'the social and the individual' and the role of human agency (2008). What represents the best option in terms of access to WSS to move out of UWSP varies from person to person and tends to change over time. Janeth maintains her basic access to WSS in order to expand her savings for a better livelihood opportunity but her needs are likely to change if and when she decides to settle down and start a family. For Mary, a water connection on their premises was initially unattainable but became a feasible step out of UWSP later on due to the increasing number of tenants. People's agency can therefore not be reduced to their social identity simply along categories like race, gender, social class or economic capacity. A relational perspective draws attention to power dynamics between the social and the individual and the various stories illustrate how these gain prominence at different times. Certain individual practices like private boreholes can offer improvements to UWSP in the absence of supporting structural conditions but not for everyone within a settlement. What is more, unless changes are implemented at the micro and macro-level to regulate borehole construction and groundwater abstraction these practices will eventually lead to depleting water sources and increased UWSP instead of presenting replicable long-term solutions.

The personal trajectories from Kombo residents have brought new voices and untold stories to the discussion on UWSP. They juxtapose and reject the flat and static ontology that is upheld in hegemonic discourses by offering alternative narratives. The needs of the 'urban water and sanitation poor' cannot be met by falsely treating them as a homogeneous group as this reinforces prevailing unequal power relations and discriminations, both between the universal groupings of the 'urban water and sanitation poor' and the 'non-poor' as well as within them. 


\section{References}

Allen A (2012) Water provision for and by the peri-urban poor: Public-community partnerships or citizens co-production? In: Vojnovic I (ed) Sustainability: A Global Urban Context. Michigan State University Press, East Lansing MI, pp 309-340

Aristizabal N (2004) Improving security without titles in Bogotá. Habitat Int 28:245-258. doi: 10.1016/S0197-3975(03)00075-4

Batty M, Brewer T, Carter R, et al (2011) Off-track, off-target: Why investment in water, sanitation and hygiene is not reaching those who need it most. WaterAid, London

Bayliss K, and Tukai R (2011) Services and supply chains: The role of the domestic private sector in water service delivery in Tanzania. UNDP, New York

Choo HY, and Ferree MM (2010) Practicing Intersectionality in Sociological Research: A Critical Analysis of Inclusions, Interactions, and Institutions in the Study of Inequalities. Sociol Theory 28:129-149. doi: 10.1111/j.1467-9558.2010.01370.x

Christensen A-D, and Jensen SQ (2012) Doing Intersectional Analysis: Methodological Implications for Qualitative Research. NORA - Nord J Fem Gend Res 20:109-125. doi: $10.1080 / 08038740.2012 .673505$

DAWASA (2000) Tanzania Case Study: Strengthening the capacity of water utilities to deliver water and sanitation services, environmental health and hygiene education to low-income urban communities. DAWASA and Water Utility Partnership, Dar es Salaam

Dhamoon RK (2011) Considerations on Mainstreaming Intersectionality. Polit Res Q 64:230-243. doi: $10.1177 / 1065912910379227$

Ekers $M$, and Loftus A (2008) The power of water: developing dialogues between Foucault and Gramsci. Environ Plan D Soc Sp 26:698-718. doi: 10.1068/d5907

Fraser N (2007) Identity, Exclusion, and Critique: A Response to Four Critics. Eur J Polit Theory 6:305338. doi: $10.1177 / 1474885107077319$ 
GIZ (2013) Kiosk Service Options for Water Utilities in Tanzania. GIZ, Dar es Salaam

Gosling L (2010) Equity and inclusion: A rights-based approach. WaterAid, London

Hancock A-M (2007) When Multiplication Doesn't Equal Quick Addition: Examining Intersectionality as a Research Paradigm. Perspect Polit 5:63-79. doi: 10.1017/S1537592707070065

Hankivsky O (2012) Women's health, men's health, and gender and health: Implications of intersectionality. Soc Sci Med 74:1712-1720. doi: 10.1016/j.socscimed.2011.11.029

Hofmann P (2011) Falling through the net: access to water and sanitation by the peri-urban water poor. Int J Urban Sustain Dev 3:40-55. doi: 10.1080/19463138.2011.577274

Hofmann P (2013) Trajectories of urban water poverty: Understanding institutional framings and approaches. Unpublished MRes dissertation, Centre for Urban Sustainability and Resilience. UCL, London

Hofmann P (2016) Institutional Discourses on Urban Water Poverty, Considering the Example of Dar es Salaam, Tanzania: Reconciling Justice and Resilience? In: Allen A, Griffin L, Johnson C (eds) Environmental Justice, Urbanization and Resilience in the Global South. Palgrave, London

Homeless International (2011) How do land tenure issues affect sanitation provision for the urban poor? Learning Brief December 2011: No. 1. 1-5

JMP Technical Task Force (2011) JMP Technical Task Force Meeting on Monitoring progress in water supply and sanitation - challenges in urban settings, Nanyuki, Kenya, 6-9 June 2011. World Health Organization and UNICEF

Kombe WJ, Ndezi T, and Hofmann P (2015) Water Justice City Profile: Dar es Salaam, Tanzania, Translocal Learning for Water Justice: Peri-Urban Pathways in India, Tanzania and Bolivia. UCL Bartlett Development Planning Unit, London

Lamsal M (2012) The Structuration Approach of Anthony Giddens. Himal J Sociol Antropol V:111-122

Levy C (2010) Viewpoint: Gender justice in a diversity approach to development?: The challenges for development planning. Int Dev Plan Rev 31:i-xi. doi: 10.3828/idpr.2009.6 
Lincoln Institute of Land Policy (2015) Understanding and Measuring Urban Expansion. http://www.lincolninst.edu/subcenters/atlas-urban-expansion/understanding-urbanexpansion.aspx. Accessed 3 Sep 2015

Maynes MJ, Pierce JL, and Laslett B (2008) Telling Stories. Cornell University Press, New York

McCall L (2005) The Complexity of Intersectionality. Signs J Women Cult Soc 30:1771-1800. doi: $10.1086 / 426800$

Mitlin D, and Satterthwaite D (2013) Urban Poverty in the Global South: Scale and nature. Earthscan, London

Mkanga M, and Ndezi T (2014) Building citywide sanitation strategies from the bottom up: A situational analysis for Dar es Salaam City, Tanzania. SHARE, London

Nash JC (2008) intersectionality. Fem Rev 89:1-15.

OHCHR, UN-HABITAT, and WHO (2010) The Right to Water, Fact Sheet No. 35. Office of the United Nations High Commissioner for Human Rights, Geneva

Pigeon M (2012) Transnational Institute From Fiasco to DAWASCO: Remunicipalising Water Systems in Dar es Salaam, Tanzania. In: Pigeon M, McDonald DA, Hoedeman O, Kishimoto S (eds) Remunicipalisation: Putting Water Back into Public Hands. Transnational Institute, Amsterdam, pp $40-57$

Potts D (2012) Viewpoint: What do we know about urbanisation in sub-Saharan Africa and does it matter? Int Dev Plan Rev 34:v-xxii. doi: 10.3828/idpr.2012.1

Prins B (2006) Narrative Accounts of Origins: A Blind Spot in the Intersectional Approach? Eur J Women's Stud 13:277-290. doi: 10.1177/1350506806065757

Saatcioglu B, and Corus C (2014) Poverty and Intersectionality: A Multidimensional Look into the Lives of the Impoverished. J Macromarketing 34:122-132. doi: 10.1177/0276146713520600

Scott P (2013) Dealing with land tenure and tenancy challenges in water and sanitation services delivery. WSUP (Water \& Sanitation for the Urban Poor), London 
Scott P, Cotton A, and Sohail Khan M (2013) Elsevier LtdTenure security and household investment decisions for urban sanitation: The case of Dakar, Senegal. Habitat Int 40:58-64. doi: 10.1016/j.habitatint.2013.02.004

Seward JE (2014) An Intersectional Approach to Environmental Political Theory: A Case Study on Modern Andean Bolivian Indigenous Forms of Resistance and Communal Democracy in Relation to Water Rights, Scripps Senior Theses, Paper 509

Sewell WHJ (1992) A Theory of Structure : Duality, Agency, and Transformation. Am J Sociol 98:1-29.

SNV, WaterAid, and UNICEF (2008) School WASH in Tanzania; Improving WASH in Schools: Improving the Quality of Education School WASH in Tanzania. SNV, WaterAid, and UNICEF, Dar es Salaam

Somers MR (1994) The Narrative Construction of Identity: a Relational and Network Approach. Theory Soc 23:605-649.

Stephens S, Schermbrucker N, and Esteves Mills J (2013) The important relationship between landlords and tenants in improving sanitation. SHARE, London

Symington A (2004) Intersectionality: A Tool for Gender and Economic Justice. Women's Rights Econ Chang 9:1-8.

Thomas J, Holbro N, and Young D (2013) A Review of Sanitation and Hygiene in Tanzania. DFID, London

Trémolet S, and Muruka G (2013) Evaluating the potential of microfinance for sanitation in Tanzania. SHARE, London

UNICEF, and WHO (2015) 2015 Update and MDG Assessment. UNICEF and World Health Organization, New York and Geneva

UNICEF, and WHO (2011) Drinking Water Equity, Safety and Sustainability: Thematic report on drinking water 2011. UNICEF and World Health Organization, New York and Geneva

UNICEF, and WHO (2012) Progress on Drinking Water and Sanitation: 2012 Update. WHO/UNICEF Joint Monitoring Programme for Water Supply and Sanitation, New York and Geneva 
WaterAid (2013) Everyone, everywhere: A vision for water, sanitation and hygiene post-2015. WaterAid, London

WHO (2012) GLAAS 2012 Report: UN-Water Global Analysis and Assessment of Sanitation and Drinking-Water. The Challenge of Extending and Sustaining Services. World Health Organization, Geneva

WHO, and UNICEF (2015) WASH Post-2015: Proposed indicators for drinking water, sanitation and hygiene. WHO/UNICEF Joint Monitoring Programme for Water Supply and Sanitation, Geneva

Yuval-Davis N (2011) Institut for Kultur og Globale Studier, Aalborg UniversitetPower, intersectionality and the politics of belonging, FREIA Working Paper Series, Working paper no. 75. Institut for Kultur og Globale Studier, Aalborg Universitet, Aalborg

Yuval-Davis N (2006) Intersectionality and Feminist Politics. Eur J Women's Stud 13:193-209. doi: $10.1177 / 1350506806065752$ 